\title{
Evaluation of Laser Drilling of Ni Film on Silicon for Solid Oxide Fuel Cells
}

\author{
Mindaugas MACIULEVIČIUS ${ }^{* 1}$, Bogdan VOISIAT ${ }^{* 1}$, Mindaugas GEDVILAS $^{* 1}$, Brigita ABAKEVIČIENË $\dot{\text { B }}^{* 2}$, Sigitas $^{*}$ \\ TAMULEVIČIUS $^{* 2}$ and Gediminas RAČIUKAITIS ${ }^{* 1}$ \\ ${ }^{* 1}$ Center for Physical Sciences and Technology, Savanoriu Ave. 231, Vilnius, LT-02300, Lithuania \\ E-mail: mindaugasm@ar.fi.lt \\ ${ }^{* 2}$ Institute of Material Science, Kaunas University of Technology, Donelaicio str. 73, LT-44029 \\ Kaunas, Lithuania
}

\begin{abstract}
During the recent years great attention was paid to develop the production technologies of micro fuel cells with a few watts of output that can be applied in the portable electrical devices. Porous nickel is an important part on many types of solid oxide fuel cells. This work presents initial results of experiments on laser drilling of micro-holes in thin $(\sim 25 \mu \mathrm{m})$ nickel foil and $200 \mathrm{~nm}$ thickness nickel films for the fuel cell membranes. The laser ablation and drilling parameters were evaluated using nanosecond and picosecond lasers running at different wavelengths. Higher pulse energy from nanosecond laser is more favorable for percussion drilling of the free-standing Ni foils. Holes as small as $2 \mu \mathrm{m}$ in diameter were drilled in the $200 \mathrm{~nm}$-tick nickel film, but the process was too slow for practical applications. Fast drilling process by parallel drilling of Ni films on silicon was realized using the laser beam interference ablation with nanosecond laser, generating $532 \mathrm{~nm}$ wavelength.
\end{abstract}

DOI:10.2961/jlmn.2011.03.0005

Keywords: laser drilling, nickel films, solid oxide fuel cell, free standing membrane

\section{Introduction}

The demand for small mobile energy storage devices and mobile power delivery systems has increased over the recent few years with the development of portable electronic devices. Fuel cells, electrochemical devices, that convert chemical energy directly into electricity, are often discussed to satisfy this demand. Several different types of fuel cells, classified according to the material of the electrolyte, have been developed and reported in the literature. Micro-solid oxide fuel cells (micro-SOFC) are predicted to be of high energy density and are potential power sources for portable electronic devices. A micro-SOFC system consists of a fuel cell comprising a positive electrodeelectrolyte-negative electrode (i.e. PEN) element, a gasprocessing unit, and a thermal system where processing is based on micro-electro-mechanical-system fabrication techniques. $\mu$-SOFCs have attracted attention because of their potential for achieving efficient energy conversion [1]. The most efficient micro fuel cells are expected to be produced using crystalline silicon as a construction material. The energy density for this type of cells is expected to be at least four times higher than that for the lithium-ion or nickel-hydride batteries (Fig. 1). Technology of this type of micro fuel cells is based on the thin films technologies. Various approaches have been proceeded to fabricate micro-SOFCs. Most of them are using a porous Ni substrate for proton exchange membrane. The pore size of such structures should be in the range of $0.2-2 \mu \mathrm{m}$, and the porosity of the free-standing film should exceed $~ 30 \%$ [2]. The silicon based micro-SOFCs consist of free-standing membranes that are fabricated with a supporting metal grid [3]. The nickel grid not only leads to a higher mechanical stability of membrane but also is used as the current collector on the anode site. Nickel is one of the best catalysts for hydrogen oxidation [2]. Therefore, nickel film is top-most important for performance of micro-SOFCs.

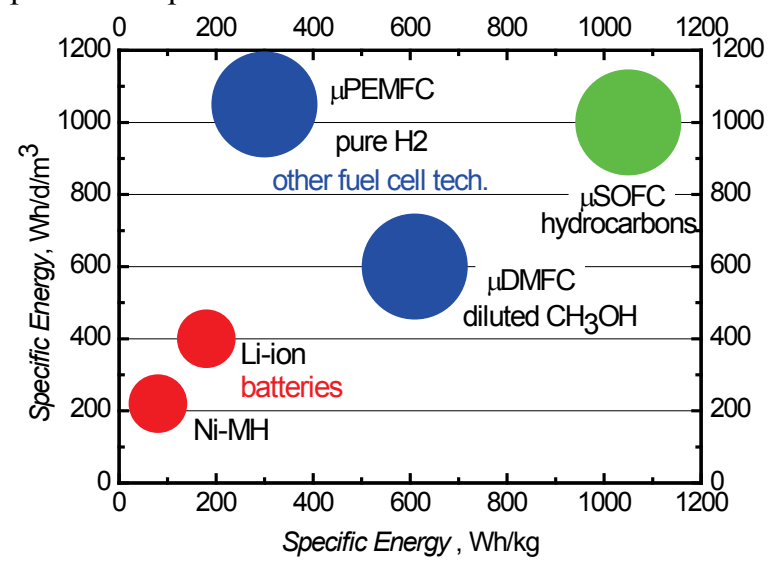

Fig. 1 Energy density of batteries and anticipated energy density of micro-fuel cells including their fuel tank (adapted from [4]).

The laser radiation has been used for thin metal film structuring for a long time. However, the small holes are difficult to achieve by simple focusing of the laser beam. The interference technique offers new opportunities of efficient production of microstructures [5-7]. Moreover, the size of structures, fabricated by interfering laser beams, is in the same range as the pore size of $\mu$-SOFC membrane [8].

In this paper we present evaluation results of laser drilling regimes of free-standing nickel foil and films on silicon using diverse laser sources. Parallel processing using the laser beam interference ablation was applied as well to the thin films. The experiments are an initial step toward reliable micro-structuring of nickel membrane layers for microSOFCs. 


\section{Percussion drilling of nickel foil and film}

\subsection{Experimental set up for laser drilling of nickel foil}

In this study, two lasers were used in experiments. Their parameters are shown in Table 1. The first laser was the Q-switched diode-pumped nanosecond Nd:YAG laser (NL220/SH, Ekspla) which generated at the wavelength of $532 \mathrm{~nm}$ and a pulse length was of approximately $9 \mathrm{~ns}$. The second one was a mode-locked Nd:YVO 4 laser (PL10100, Ekspla) working at the wavelength of $1064 \mathrm{~nm}$, with additional second and third harmonic generators. The more detailed description about this setup is presented in [9].

The lasers were used in conjunction with a galvanometric scanner and the telecentric objectives or samples were moved by computer-controlled XYZ stages, relative to the fixed laser beam. For all laser systems, an external Pockels cell was used for the selection of the pulse numbers and pulse energy control.

Table 1 Parameters of the lasers used in drilling experiments.

\begin{tabular}{lll}
\hline & NL220SH & PL10100 \\
\hline Wavelength, $\mathrm{nm}$ & 532 & $1064 / 532 / 355$ \\
\hline \hline Repetition rate, $\mathrm{kHz}$ & 0.5 & 100 \\
\hline \hline Average output power, $\mathrm{W}$ & $>1.1$ & $10 / 4 / 2$ \\
\hline \hline Max. pulse energy & $2.2 \mathrm{~mJ}$ & $200 / 80 / 40 \mu \mathrm{J}$ \\
\hline \hline Pulse duration & $9 \mathrm{~ns}$ & $10 \mathrm{ps}$ \\
\hline
\end{tabular}

Optical (Olympus BX51TF) and scanning electron microscope (JEOL JSM-6490 LV) were used to evaluate the drilling results.

\subsection{Laser drilling of nickel foil}

Percussion drilling was used to penetrate the Ni foils with the thickness of $25 \mu \mathrm{m}$. First of all, the ablation threshold for Ni foil was evaluated using all the laser systems. Arrays of holes were drilled by changing the pulse energy and the number of laser pulses per hole. Diameters of craters ablated at different pulse energies were measured and plotted versus laser fluence (Fig. 2). Linear fit was used in a special coordinate system according to the method proposed by Liu [10]. Similar procedures were performed for all lasers used in experiments. The values for ablation threshold are presented in Table 2.

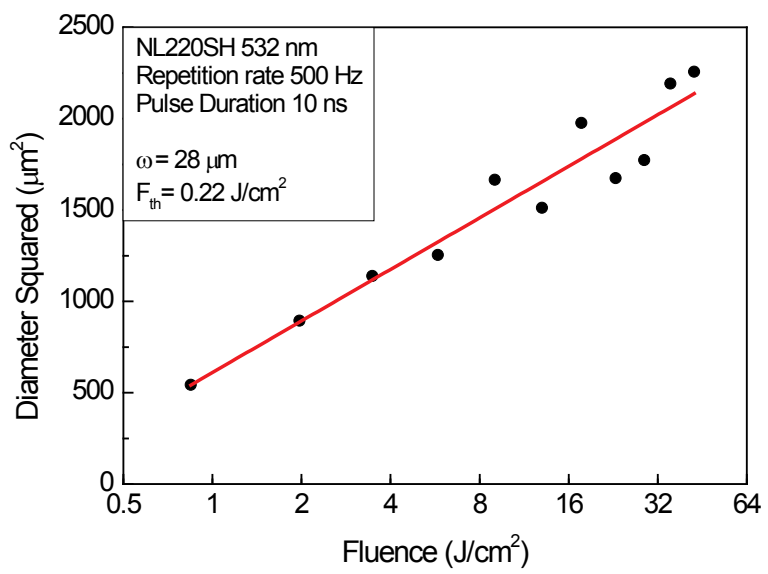

Fig. 2 Diameter of the craters ablated in nickel foil versus laser fluence. Ablation threshold was $0.22 \mathrm{~J} / \mathrm{cm}^{2}$; spot radius $28 \mu \mathrm{m}$. (Laser: NL220/SH, laser pulse duration $9 \mathrm{~ns}$, wavelength $532 \mathrm{~nm}$ ).
Table 2 Ablation thresholds of nickel.

\begin{tabular}{ccc}
\hline Wavelength & $\begin{array}{c}\text { Pulse } \\
\text { duration }\end{array}$ & $\begin{array}{c}\text { Ablation } \\
\text { threshold }\end{array}$ \\
\hline $1064 \mathrm{~nm}$ & $10 \mathrm{ps}$ & $1.2 \mathrm{~J} / \mathrm{cm}^{2}$ \\
$532 \mathrm{~nm}$ & $10 \mathrm{ps}$ & $0.5 \mathrm{~J} / \mathrm{cm}^{2}$ \\
$355 \mathrm{~nm}$ & $10 \mathrm{ps}$ & $1.6 \mathrm{~J} / \mathrm{cm}^{2}$ \\
$532 \mathrm{~nm}$ & $9 \mathrm{~ns}$ & $0.2 \mathrm{~J} / \mathrm{cm}^{2}$ \\
\hline
\end{tabular}

For further experiments with $\mathrm{Ni}$ foils, the nanosecond laser with high pulse energy was selected. It was found that using percussion drilling of $25 \mu \mathrm{m}$ thickness nickel foil the holes of size $10 \mu \mathrm{m}$ can be simply achieved. The exit diameter of holes stabilized after 100-200 laser pulses (Fig. 3). This means that even with quite high pulse energy 100-200 laser pulses per spot need to be used in order to produce an array of equal sized micro-holes.

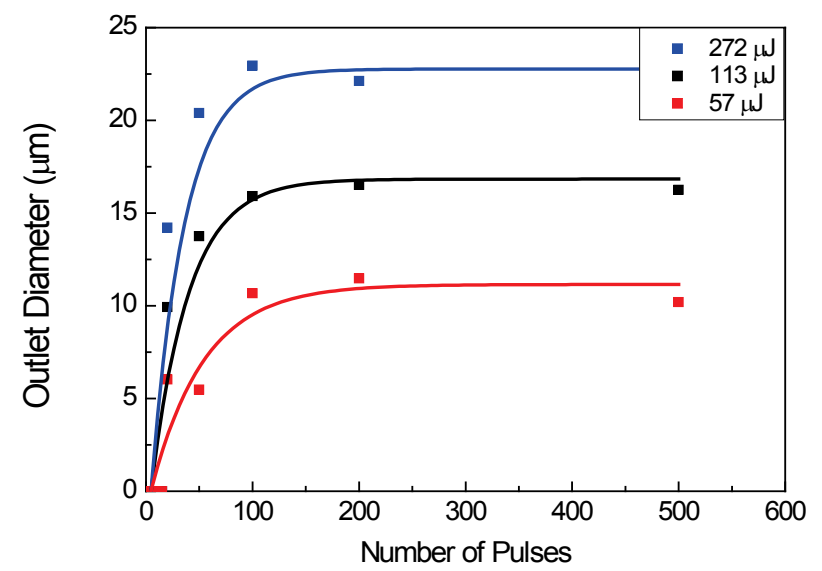

Fig. 3 Holes in the nickel foil with thickness of $25 \mu \mathrm{m}$ : exit diameter versus the applied number of laser pulses.

We applied this regime to drill an array of holes in area of $1 \mathrm{x} 1 \mathrm{~cm}^{2}$ with the distance between holes equal to $50 \mu \mathrm{m}$. With the pulse repetition rate of $500 \mathrm{~Hz}, 40000$ holes were drilled in almost three hours (Fig. 4). This is too slow process for efficient production of $\mu$-SOFC membranes.
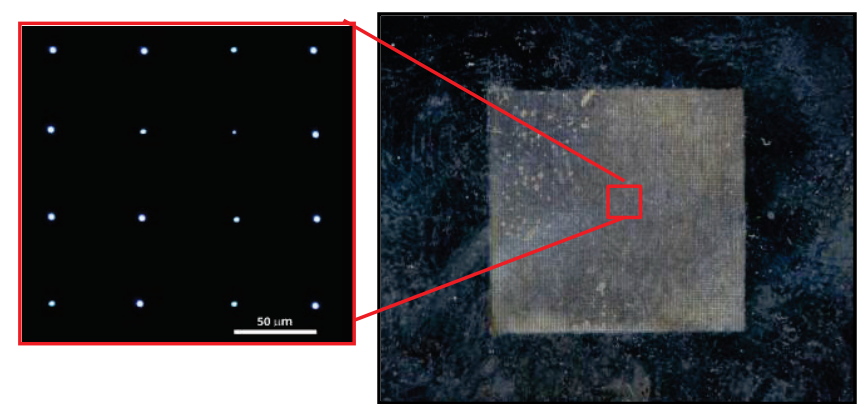

Fig. 4 A picture of a matrix of holes in the $25 \mu \mathrm{m}$-thick nickel foil. Eit diameter of holes is about $8 \mu \mathrm{m}$ and distance between holes $50 \mu \mathrm{m}$. (Laser NL220/SH: pulse energy $E \mathrm{p}=57 \mu \mathrm{J} ; 100$ pulses).

\subsection{Laser drilling of nickel film on silicon}

Percussion drilling was also tested to drill the Ni film with the thickness of $200 \mathrm{~nm}$ deposited on a silicon wafer. Again, arrays of holes were drilled by changing the pulse energy and the number of laser pulses per hole using different lasers and wavelength. Fig. 5 presents SEM pictures 
of selected holes, drilled with nanosecond (9 ns) and picosecond (10 ps) lasers.

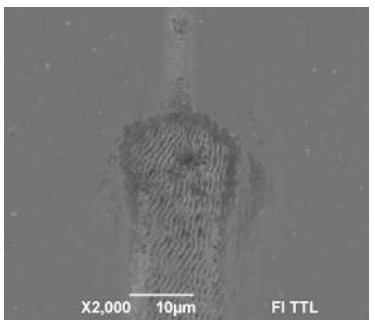

a)

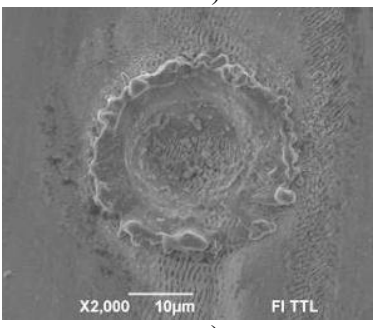

c)

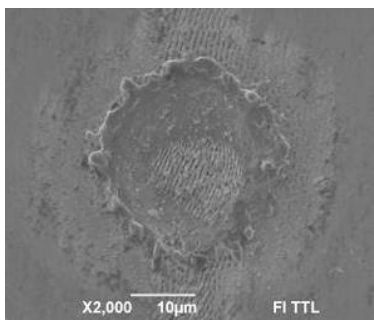

b)

d)

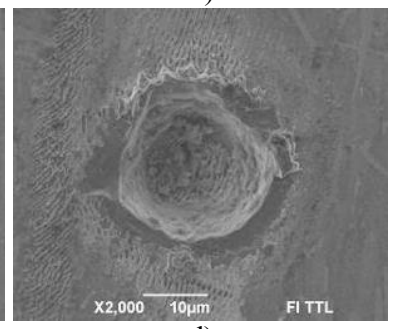

Fig. 5 SEM pictures of holes ablated in nickel foil effect of the number of pulses N: (a) $N=1$; (b) $N=5$; (c) $N=10$ s; (d) $N=20$. Laser parameters: PL10100/SH; pulse energy $E_{\mathrm{p}}=124 \mu \mathrm{J}$; wavelength $532 \mathrm{~nm}$; pulse duration $10 \mathrm{ps}$.

Single pulse of the nanosecond laser was able to ablate through the Ni film, splashing out molten metal around and diameter of the hole was as large as $30 \mu \mathrm{m}$ (Fig. 5a). Infrared picosecond laser was able to drill through the $200 \mathrm{~nm}$ thick nickel film using 5 laser pulses and the opening in the film was reduced to about $10 \mu \mathrm{m}$ (Fig. 5b). Using the "green" radiation of the picosecond laser $(532 \mathrm{~nm})$, low pulse energy initiated ablation of the film in an area with a diameter about $3 \mu \mathrm{m}$ (Fig. 5d). Such size of holes is promising for SOFC membranes, but stable process of drilling was not achieved. When high pulse energies were applied, laser beam penetrated deep into silicon wafer (Fig. 5c). Complete drilling the silicon substrate together with the nickel film could be useful for $\mu$-SOFC production. However, such type of drilling for silicon wafers with thickness larger than $100 \mu \mathrm{m}$ lead to formation large-diameter holes, which is not appropriate for application.

\section{Drilling of Ni film using interference of laser beams}

The second approach of drilling holes for membranes for $\mu$-SOFC, which we applied in our research, was the method of laser beam interference ablation (LBIA). The method utilizes interference field at intersection of a few laser beams for direct ablation of the material.

\subsection{Experimental setup with four beams interference}

The experimental setup is shown in Fig. 6. The nanosecond laser NL220/SH (Ekspla) with pulse energy of $2 \mathrm{~mJ}$ was used in the experiments. The pulse duration at FWHM was $9 \mathrm{~ns}$. The laser generated the $532 \mathrm{~nm}$ radiation at the repetition rate of $500 \mathrm{~Hz}$. The laser was selected because of high pulse energy, and the laser fluence above the ablation threshold was maintained over a large focal area. Laser energy was controlled with the attenuator consisting of the $\lambda / 4$ plate and a polarizer. To have higher energy density, the diameter of the laser beam was reduced twice with a set of two lenses.

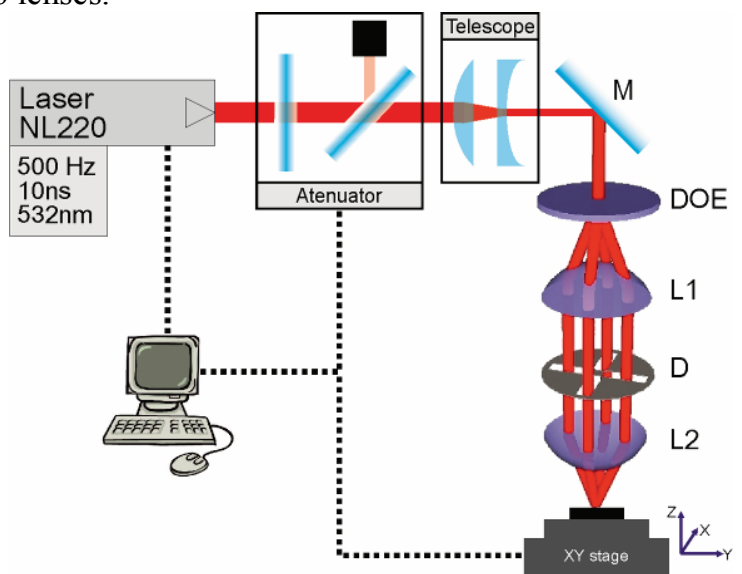

Fig. 6 Setup for the laser beam interference ablation experiments with four beams and $4 \mathrm{~F}$ imaging system. $\mathrm{M}$ - folding mirror; DOE - diffractive optical element; F1 and F2 - spherical lenses with focus length of $75 \mathrm{~mm}$ and $50 \mathrm{~mm}$.

A diffractive optical element (DOE), which is the key element of this setup, split the laser irradiation into four beams ( \pm 1 order maxima) at an angle of 5 degrees each. The splitted beams were made parallel by a lens, L1 (with focal length $75 \mathrm{~mm}$ ), then selected by an aperture to block zero and higher than \pm 1 order beams. The selected beams were gathered by a lens L2 (with focal length $50 \mathrm{~mm}$ ), and produced interference field in the focal region, where the sample was placed. The spot, where interference of beams took place, was $600 \mu \mathrm{m}$ in diameter.

The piezoelectric 2-axis positioning system KDT-180 (Feinmess) was able to move a sample in range of $100 \times 100 \mathrm{~mm}$ in $\boldsymbol{x}$ and $\boldsymbol{y}$ direction with the minimal programmable step of $200 \mathrm{~nm}$. It was used for scanning the sample under the laser beam between exposures. Laser pulse energy, number of laser pulses and positioning were controlled with computer software.

The intensity distribution of the four-beam interference is expressed by equation [10]:

$I(\vec{r})=\frac{1}{2} \sum_{i} E_{0 i}^{2}+\sum_{i<j} E_{0 i} \cdot E_{0 j} \cos \left(\left(\vec{k}_{i}-\vec{k}_{j}\right) \cdot \vec{r}+\varepsilon_{i}-\varepsilon_{j}\right)$,

where $E_{i}$ is the electrical field, $\vec{k}_{i}$ is the wave vector and $\varepsilon_{i}$ is the phase of each of four laser beams and $\vec{r}$ is the coordinate vector. Indexes denote the laser beams: 1, 2, 3 and 4.

The intensity profile, created by the optical setup described in second section when no phase difference was between beams pairs, was a periodical structure with maxima in quadratic matrix arrangement (Fig. 7).

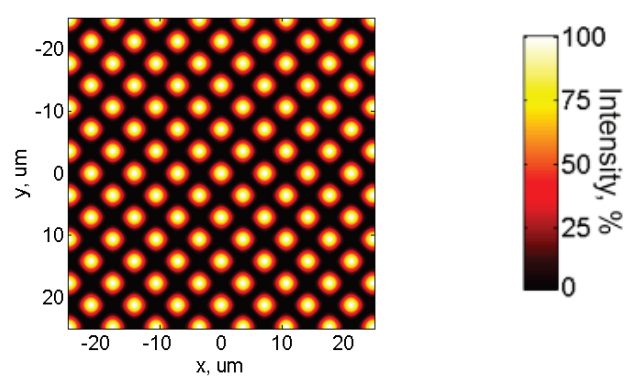

Fig. 7 Intensity distribution of 4 interfering beams. 


\subsection{Results of drilling by LBIA}

In this part of experiments, we tested the four-beams interference ablation of $200 \mathrm{~nm}$ nickel film deposited on a silicon wafer. Different pulse energy and the number of laser pulses per spot without any shift of a workpiece were used in experiments. Due to 4-beam interference, the resulting structure ablated in the films was quadratic matrix of circular holes with a period of $4.2 \mu \mathrm{m}$ (Fig. 8).

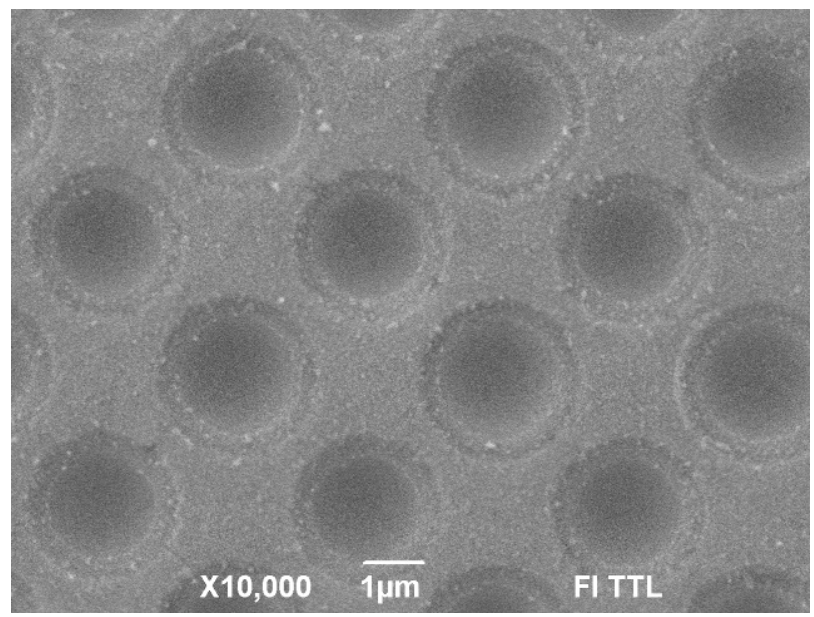

Fig. 8 SEM image of periodical structure made on $200 \mathrm{~nm}$ nickel film deposited on silicon wafer. Laser pulse energyr $-0.8 \mathrm{~mJ}$, the number of pulses -100 .

The diameter of holes depended on the pulse energy and the number of pulses, and it was in range from 1.7 to $2.7 \mu \mathrm{m}$. Fig. 9 shows how the diameter of holes depends on the peak energy density at different number of pulses.

Laser fluence was too low to ablate the holes through the nickel layer until the silicon wafer with the only a single pulse, therefore more than 10 laser pulses were needed. The pulse energy was distributed over the whole respectively large beam area of $600 \mu \mathrm{m}$ in diameter with a few thousands of intensity maxima.

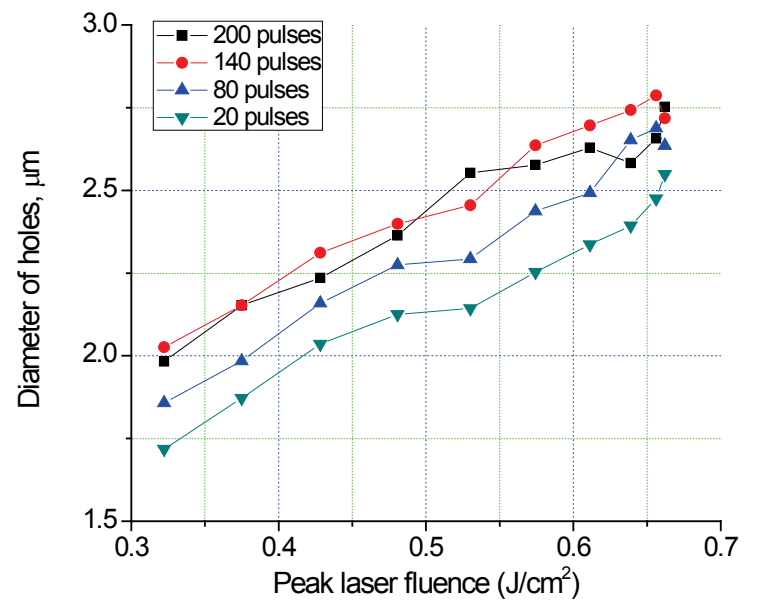

Fig. 9 Diameter of holes, fabricated with 4-beams interference ablation, depending on laser peak energy density when different number of pulses was used.

The area where holes were ablated was approximately $250 \times 250 \mu \mathrm{m}$ (Fig. 10). The area of this size contains about 4000 holes. Its size varied slightly $( \pm 30 \mu \mathrm{m})$ with different number of pulses and energies.

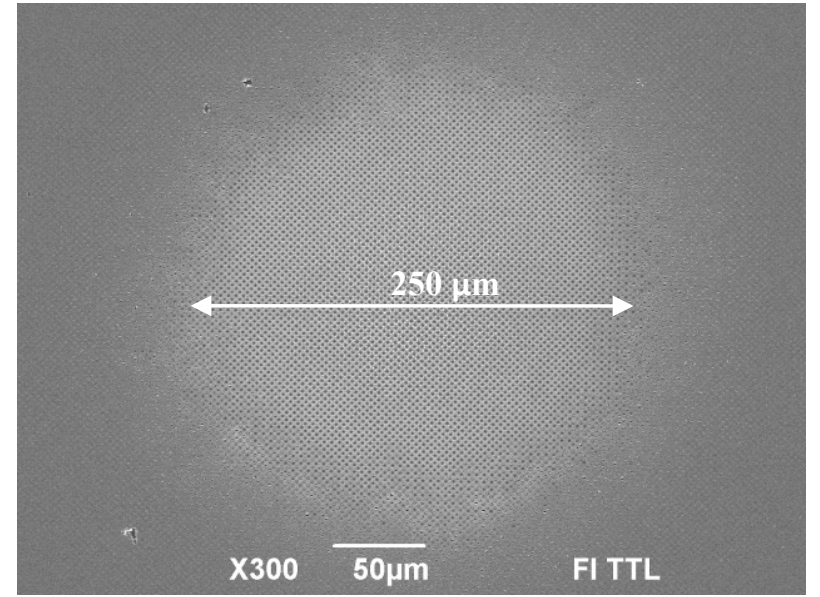

Fig. 10 SEM image of the area consisting of $\sim 4000$ circular holes ablated in $200 \mathrm{~nm}$ nickel film with 100 laser pulses (Pulse energy $-0.8 \mathrm{~mJ}$ ) using four-beams interference ablation.

It is well known that, when ablation is performed with the Gaussian beam, the cross-section of ablated crater has a conical shape. It is therefore possible to get such processing parameters, that only a top of the cone reaches the silicone plate, and forms a very small hole. Such holes, with a diameter of $200 \mathrm{~nm}$, were formed when 10 laser pulses with $1 \mathrm{~mJ}$ energy were used to ablate the nickel film (Fig. 11).

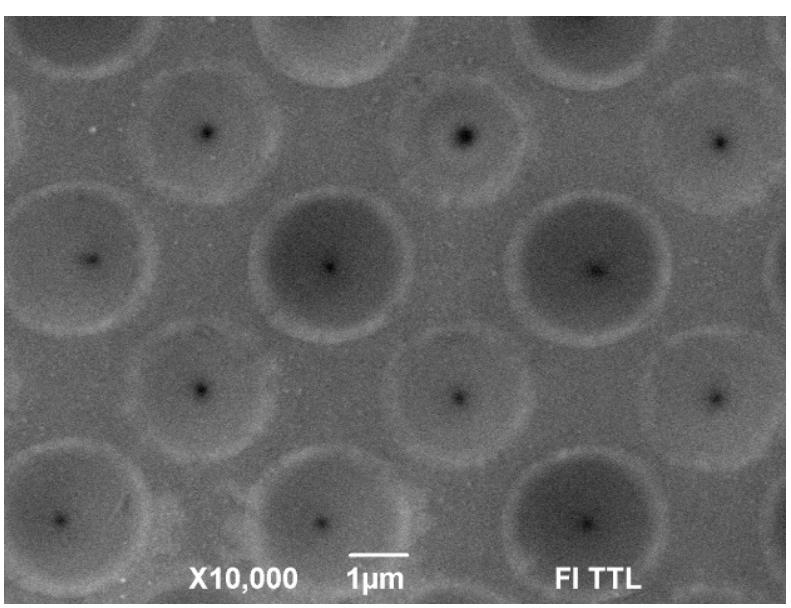

Fig. 11 SEM image of periodical structure made on 200 nm nickel film deposited on a silicon wafer. Laser pulse energy $-1 \mathrm{~mJ}$, the number of pulses -10 .

In most cases, we applied in our experiments more than one laser pulse to penetrate even thin nickel film. Xie et. al. have shown that in some cases the better laser percussion drilling results can be achieved using a slower drilling process by varying the energy of the laser pulses [12]. We tested this approach with our laser beam interference ablation technique. Holes were drilled in nickel film by increasing the energy of each successive pulse using different functions for variation. Three types of energy increase distributions were used: linear growth, slow and fast exponential growth. The results are shown in Fig. 12. It can be seen that the when growing pulse energy was used, ablated holes were irregularly shaped. When, at first, the pulses with a low energy are applied, they only melt the metal and do not initiate any ablation. This melted metal solidifies and causes the irregularity in shape of the holes. 


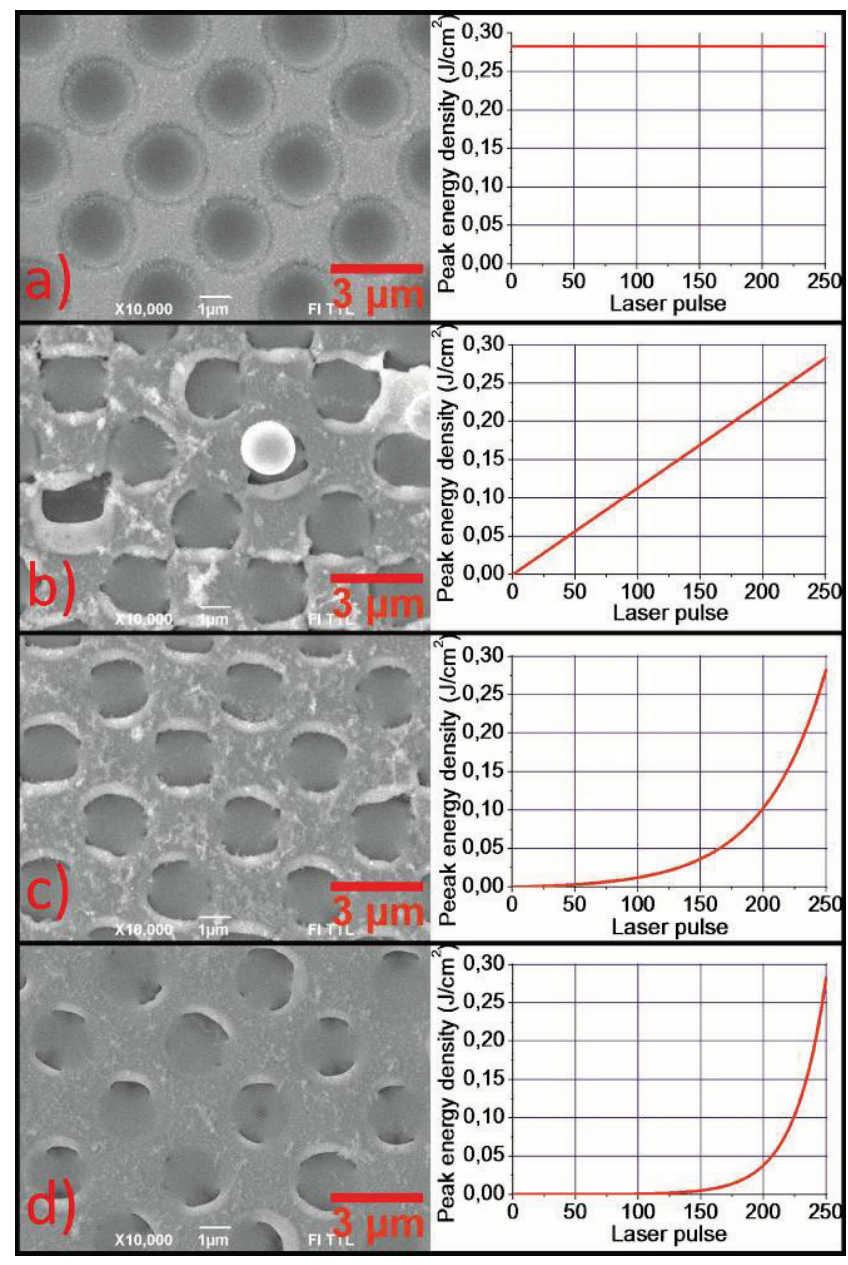

Fig. 12 SEM pictures of holes drilled in nickel film on silicon wafer with different laser energy growing distribution: a) constant pulse energy; b) linearly increase; c) "slow" exponential grow of energy of successive laser pulses; d) "fast" exponential grow of energy of successive laser pulses. Variation of the pulse energy is shown on the right side.

The method of the varying laser pulse energy permitted in some content to control the shape of the holes in the thin metal film. Nearly rectangular holes were drilled in the film, when the "slow" exponential growth of pulse energy was used. However, shape of the holes became unstable or even damage in the film appeared. Therefore, drilling holes with constant pulse energy remains as the most appropriate method.

\section{Summary}

An ablation threshold for nickel foil was estimated using nanosecond and picosecond lasers. It has been shown that the lowest ablation threshold for nickel is using the $532 \mathrm{~nm}$ laser radiation. Holes as small as $10 \mu \mathrm{m}$ were drilled in the $25 \mu \mathrm{m}$ thick Ni foil membranes using percussion drilling.

It was demonstrated that formation of micro-channels over a large area in the thin-film membranes of fuel cells is feasible using the four beam interference ablation. Using this technique, circular holes in quadratic matrix arrangement with a period of $4.2 \mu \mathrm{m}$ were formed in the $200 \mathrm{~nm}$ thick nickel film. The diameter of the holes ranged from 1.7 to $2.7 \mu \mathrm{m}$. The area where holes were ablated was approximately $250 \times 250 \mu \mathrm{m}$.

\section{Acknowledgment}

This research was funded by a grant No. ATE-05/2010 from the Research Council of Lithuania.

\section{References}

[1] P.-C. Su, C.-C. Chao, J.H. Shim, R. Fasching, F.B. Prinz: Nano Letters, 8, (2008) 2289.

[2] J.H. Joo, G.M. Choi:. J. Power Sources, 182, (2008) 589.

[3] A. Evans, A. Bieberle-Hütter, J.L.M. Rupp, L.J. Gauckler: J. Power Sources, 194, (2009) 119.

[4] A. Evans, A. Bieberle-Hütter, H. Galinski, J. Rupp, T. Ryll, B. Scherrer, R. Tölke, L. Gauckler: Chemical Monthly, 140, (2009) 975.

[5] S. Riedel, M. Schmotz, P. Leiderer, J. Boneberg: Appl. Physi. A, 101, (2010) 309.

[6] B. Voisiat, M. Gedvilas, G. Raciukaitis: Proc. Int. Congress on Applications of Lasers \& Electro- Optics, ICALEO 2010, Anaheim, California, USA, 2010; ISBN\# 978-0-912035-61-1, LIA pub. \#613.

[7] B. Voisiat, M. Gedvilas, S. Indrisiunas, G. Raciukaitis: Physics Procedia, 12(2), (2011) 116.

[8] Y. Yan, S. Rey-Mermet, Z.B. He, G. Deng, P. Muralt: Procedia Chemistry, 1, (2009) 1207.

[9] M. Maciulevicius, M. Gedvilas, B. Abakeviciene, S. Tamulevicius, G. Raciukaitis: Physics Procedia, 12(2), (2011) 320 .

[10] J. M. Liu: Optics Letters, 7, (1982) 196.

[11]E. Molotokaitè, M. Gedvilas, G. Račiukaitis: J. Laser Micro/Nanoengineering, 5, (2010) 74.

[12]X. S. Xie, M. Li, J. Guo, B. Liang, Z. X. Wang, A. Sinitskii, Y. Xiang, J. Y. Zhou: Opt. Express, 15, (2007) 7032 .

(Received: June 07, 2011, Accepted: October 31, 2011) 